\title{
Effects of selected antioxidant food extracts on postprandial glucose responses in healthy individuals
}

\section{Lynne Chepulis $^{1}$, Hayder Al- Aubaidy ${ }^{2}$, Rachel Page ${ }^{3}$}

${ }^{1}$ Department of Nursing, Faculty of Health, Education and Humanities, Waiariki Institute of Technology, Rotorua, New Zealand; ${ }^{2}$ School of Medicine, University of Tasmania, Hobart, Tasmania, Australia; ${ }^{3}$ School of Food and Nutrition, Massey University, Wellington, New Zealand

*Corresponding Author: Lynne Chepulis, Department of Nursing, Faculty of Health, Education and Humanities, Waiariki Institute of Technology, Rotorua, New Zealand

Submission Date: June 7, 2016, Accepted Date: August 24, 2016, Publication Date: August 30, 2016

\begin{abstract}
Background: Obesity and diabetes are highly prevalent in Western countries. Both of these conditions can be associated with impaired glucose control and hyperglycemia. Studies have identified that antioxidants have the ability to regulate blood glucose levels. However, the effects of specific high-antioxidant food extracts on blood glucose levels have not been well characterized. Thus, this study aimed to measure the effects of selected antioxidant food extracts on postprandial glucose responses in healthy individuals.
\end{abstract}

Methods: Ten healthy individuals were recruited into a randomized, single-blinded study. Participants consumed five different high-antioxidant food extracts (one per session, each $>48$ hours apart) that were matched for total antioxidant content $10 \mathrm{mins}$ prior to ingestion of $50 \mathrm{~g}$ of available carbohydrate from either a glucose load or white bread (with ham) after an overnight fast. Blood glucose levels were measured using capillary sampling every 15 mins for two hours and the incremental area under the glucose curve (IAUC) was also measured. The IAUC values for the test foods were compared to the glucose-only and bread-only controls.

Results: Amla berry-, grape seed- rooibos tea- and green tea- extracts as well as propolis tincture were all strong glycemic modulators, significantly decreasing the IAUC by $25-40 \%$ compared to the glucose-only or white bread controls (all $\mathrm{p}<0.05$ ).

Conclusion: Antioxidants are able to modulate postprandial glucose responses in healthy subjects. These results suggest that further research is warranted to determine whether these antioxidant-rich foods are beneficial to people with prediabetes or type 2 diabetes mellitus.

Keywords: Antioxidants, glycemic response, blood glucose levels, postprandial response 


\section{BACKGROUND:}

Hyperglycemia and insulin resistance are the main pathophysiological changes behind the development of prediabetes and type 2 diabetes mellitus (T2DM) [1]. T2DM is of particular concern due to its high prevalence, high incidence, chronicity and potential for long-term implications which include vascular and neuropathic degeneration [1]. Worldwide, it has been estimated that as many as 380 million people suffer from T2DM, which is why this disease is considered a significant economic burden in both the Western and developing countries [2]. The economic burden resulting from diabetes is thought to be in excess of \$302 billion US dollars, without considering the complications from diabetes [2].

In the prediabetes stage, an individual may demonstrate an impaired fasting glucose (IFG) and/or impaired glucose tolerance (IGT) without fulfilling the criteria for the diagnosis of T2DM $[1,3]$. According to an American Diabetic Association (ADA) expert panel, it is believed that without intervention, the likelihood of a person with prediabetes developing full T2DM during their lifetime is around 70\% [1]. Currently, the conversion rate of prediabetes to T2DM is 5-10\% annually [3] and the prevalence of prediabetes is expected to reach a rate of 1 in 3 adults by 2050 [4].

Recent studies have revealed that dietary interventions focused on lowering the glycemic index and/or glycemic load in prediabetics are associated with a decreased incidence of T2DM [5-9]. As a result, the Public Health arm of the World Health Organization is recommending an active control of blood glucose levels as an important intervention step to slow the development and progression of prediabetes to T2DM [10]. However, maintaining an appropriately controlled glycemic response profile can be difficult in light of the fact that sugary and high GI foods are abundant in the Western diet [11]. Additionally, it has been reported that people who are unaware that they have prediabetes tend to consume more sugars and carbohydrates compared to those diagnosed with T2DM [12].

Recently, research has demonstrated that food-based antioxidants may be able to modulate blood glucose levels [13-15]. For example, studies have demonstrated that food-based antioxidants may be able to lower the postprandial glucose response in both healthy subjects and those with T2DM [13-17]. It has been suggested that foods and concentrated extracts high in antioxidants may be able to improve glycemic control, as postprandial hyperglycemia is associated with the formation of reactive oxygen species and oxidative stress [13, 18]. It has also been reported that food-based antioxidants may lower postprandial glucose responses by acting directly in the gastrointestinal tract to reduce carbohydrate digestion and absorption [19] as well as directly reducing postprandial oxidation [18, 20-22]. Food-based antioxidants may also have a protective function by scavenging oxygen free radicals and ameliorating oxidative stress [15, 23].

Many high-antioxidant food extracts are commercially available for sale, but little is known about the effects of many of these food extracts on postprandial glucose responses, particularly in people with prediabetes. The present study focuses on the use of extracts, some of which are not as well characterized in addition to phenolic-rich extracts which have not been investigated in people with prediabetes or T2DM. These include the South African rooibos tea extract, New 
Zealand (NZ) grape seed extract, NZ propolis, amla berry extract and green tea extract. The primary objective of this study was to evaluate the effects of these food extracts on the postprandial blood glucose response to a carbohydrate load in healthy subjects, with the aim of identifying food extracts that warrant further investigation in a prediabetic cohort.

\section{METHODS}

\section{Participants}

Ten healthy subjects were recruited from the student body at Waiariki Institute of Technology, Rotorua, NZ. Inclusion criteria included having a body mass index (BMI) of $18-25 \mathrm{~kg} / \mathrm{m}^{2}$, aged 18-45 years, no known food allergies, diabetes or chronic illness, and not taking any medications (other than birth control). All subjects were screened prior to inclusion for healthy values of fasting glucose $(\leq 5.7 \mathrm{mmol} / \mathrm{L})$ and glycated haemoglobin $(\mathrm{HbA} 1 \mathrm{c} \leq 38.8 \mathrm{mmol} / \mathrm{mol})$. Written informed consent was obtained from all 10 volunteers. This study was approved by the Waiariki Institute of Technology Research and Ethics Committee and was carried out in accordance with the ethical standards of the Helsinki Declaration of 1975, as revised in 2008 [24].

\section{Study Design}

This study was a randomized, controlled, single-blind study in which the effects of five antioxidant-rich foods/extracts (green tea, alma berry, grape seed, rooibos tea extracts and propolis tincture) were evaluated during single-dose feeding on postprandial glucose response in healthy individuals. The study design was based on previous reports [25, 26]. Subjects were asked to consume the antioxidant-rich food extract with either a glucose or carbohydrate (white bread) load; their effects on postprandial glucose levels were measured.

All subjects were instructed to keep their diet, body weight and living habits constant throughout the study and to refrain from intensive exercise and alcohol in the 24-hour period prior to each test session. Participants were also asked to avoid the active test foods/extracts for at least seven days prior to the first test session and throughout the duration of the test period (this included avoiding other teas and formulations where the extracts may be present).

Two studies were performed which included testing all five antioxidant-rich foods against two different carbohydrate controls/loads. Study 1 used $50 \mathrm{~g}$ of available carbohydrate from glucose (55g of D-glucose anhydrous; Hansells New Zealand Ltd in $200 \mathrm{ml}$ of water) as the control and carbohydrate load. The available carbohydrate content of the glucose was determined by AsureQuality NZ Ltd using gas chromatography as described previously [27]. Study 2 was based upon the protocol outlined by Josic et al. (2010) [25] using a simple meal (white bread and ham) as the control and carbohydrate load. This meal consisted of 50 grams of actual carbohydrate (103 grams of TipTop Supersoft White Toast bread (approx. 2.5 slices) providing 1081 kilojoules, $8.2 \mathrm{~g}$ protein, $2.1 \mathrm{~g}$ fat, $49.75 \mathrm{~g}$ carbohydrate (of which $3.5 \mathrm{~g}$ was sugar), $2.5 \mathrm{~g}$ dietary fibre and $463.5 \mathrm{mg}$ sodium) together with 25 grams of ham (Beehive sliced honey-baked ham providing $4.3 \mathrm{~g}$ protein, $0.5 \mathrm{~g}$ fat, $0.25 \mathrm{~g}$ carbohydrate (of which $0.15 \mathrm{~g}$ is sugars).

All 10 participants performed both Study 1 and Study 2. Each participant had six test sessions per study, which included a control test session and five different antioxidant food 
extract test sessions. In the first test session for each study, participants consumed the control carbohydrate and the postprandial glucose response was measured. Two blood samples were collected by capillary sampling via finger prick at $\mathrm{T}=-10 \mathrm{mins}$ then again at $\mathrm{T}=0 \mathrm{mins}$, with the latter values averaged as their baseline blood glucose concentration. Participants were asked to consume the glucose load / simple meal as quickly as possible and the two-hour countdown begun from the time of first ingestion.

For the antioxidant test sessions, the extracts were consumed 10 minutes prior to the carbohydrate load. The order of antioxidant samples was randomized for each participant, and all extracts were provided to participants in capsule form. Capillary blood samples were taken at -10 mins (time of taking capsules) and 0 mins (baseline, time of consuming carbohydrate load).

During all test sessions, further capillary blood samples were taken at 15, 30, 45, 60, 90, 105 and 120 mins. Capillary blood was analyzed immediately after collection for blood glucose concentration using a calibrated Accu-Chek Performa blood glucose meter (Roche Diagnostics, Germany).

All test sessions were carried out in the clinical laboratory in the Nursing Department at 0830 hours following a 10-hour overnight fast. Test sessions were carried out during a 4 week period, with at least 48 hours between sessions as a washout period. The half-lives of the primary bioactives of each of the test extracts were shown to be in the range of 20 minutes to 5.5 hours [28-30].

\section{Antioxidant Extracts}

The antioxidant-rich products tested in this study included i) green tea extract (Microgenics green tea 10,000), each $1.0 \mathrm{~g}$ tablet containing Camelia sinensis extract equivalent to $10,000 \mathrm{mg}$ dry leaf; equivalent polyphenols $320 \mathrm{mg}$; equivalent catechins $240 \mathrm{mg}$; equivalent epigallocatechin-3-0-gallate 120mg, ii) amla berry extract (Sharman Ltd, Nelson, New Zealand), each $700 \mathrm{mg}$ capsule containing Emblica officinalis fruit extract equivalent to $20 \%$ tannins), iii) propolis BIO100 capsules with zinc gluconate (Manuka Health New Zealand Ltd), each $400 \mathrm{mg}$ capsule containing $320 \mathrm{mg}$ New Zealand propolis powder; equivalent bioflavonoid content 32 mg); iv) grape seed extract (NutraLife, New Zealand Ltd), each 500 mg capsule containing grape (Vitis vinifera) extract equivalent to $40,000 \mathrm{mg}$ dry seed; equivalent procyanadins $320 \mathrm{mg}$; equivalent 10,000 fresh seed), v) rooibos tea extract (Rooibos Ltd, Clanwilliam, South Africa) containing a spray dried cold water extract of Aspalathus linearis with $\geq 30 \%$ polyphenols.

To determine the antioxidant activity of each product, samples were sent to Callaghan Innovation (Wellington, New Zealand) for measurement of total antioxidant activity using the 2,2- diphenyl-1-picrylhydrazyl (DPPH) free radical scavenging method [31] but adapted for use in a 96 well plate with measurement using a microtitre plate reader. All samples were extracted by ultrasonication at room temperature with 70:30 methanol:water containing $0.5 \%$ acetic acid.

For the purposes of comparison a vitamin E sample (with a known effective concentration half-life $\left(\mathrm{EC}_{50}\right)$ of $\left.0.44 \mathrm{mg} / \mathrm{mL}\right)$ was included. $\mathrm{EC}_{50}$ values of the food extract samples were determined to be $0.40 \mathrm{mg} / \mathrm{mL}$ (green tea extract), $2.5 \mathrm{mg} / \mathrm{mL}$ (propolis tincture), $0.20 \mathrm{mg} / \mathrm{mL}$ (grape seed extract), $0.36 \mathrm{mg} / \mathrm{mL}$ (amla berry extract) and $0.25 \mathrm{mg} / \mathrm{mL}$ (rooibos tea extract). 
All antioxidant food extracts were included in the study such that the total antioxidant activity of each sample was equivalent in each test. On a weight per weight basis this meant that participants took either one green tea extract tablet, one grape seed extract tablet, six BIO100 propolis capsules, 1.6 amla berry extract capsules (a total of 1,120 mg was delivered in two adjusted capsules) or 0.76 grams of rooibos tea extract (provided to participant in three size ' 0 ' gelatin capsules).

\section{Measurement of Glucose Response}

The control postprandial glucose responses were measured by calculating the incremental area under the blood glucose response curve (IAUC) of 50 grams of available carbohydrate from glucose (Study 1) or 50 grams of actual carbohydrate from a simple meal (Study 2). This was measured using the trapezoidal method as outlined in Woelever and Jenkins (1986) [32]. IAUC values were then calculated for all antioxidant plus carbohydrate load and compared to the glucose-only (Study 1) and bread/ham-only (Study 2) controls. For all calculations, the IUAC was determined as the area of those increments above baseline only.

\section{Statistical Analyses}

The mean IAUC of the carbohydrate controls (the glucose load and the white bread plus ham) were compared to the IAUC values of the carbohydrate plus specific antioxidant using a repeated measures ANOVA with Scheffe Post Hoc analyses. A P value of 0.05 was considered to be significant. Analyses were carried out using DataDesk ${ }^{\circledR}$ version 7.

\section{RESULTS}

\section{Participant Demographics}

The study group consisted of 10 females, all of whom had good measures of glycemic control. Ethnic diversity was seen in the study group: five participants were NZ European, three were NZ Maori, one was Pacifica and one subject was of Korean descent. The demographic details are given in Table 1.

Table 1: Participant Demographic Information

\begin{tabular}{|c|c|c|}
\hline Variable & Mean $( \pm$ SD $)$ & Range \\
\hline Age $($ years $)$ & $28 \pm 4.2$ & $19-43$ \\
\hline BMI $\left(\mathrm{kg} / \mathrm{m}^{2}\right)$ & $23.0 \pm 2.1$ & $19.3-25.0$ \\
\hline $\begin{array}{c}\text { Fasting Glucose } \\
(\mathrm{mmol} / \mathrm{L})\end{array}$ & $4.55 \pm 0.4$ & $3.9-5.0$ \\
\hline $\mathrm{HbA1c}(\mathrm{mmol} / \mathrm{mol})$ & $31.2 \pm 2.4$ & $28-34$ \\
\hline
\end{tabular}

\section{Study 1: Effects of antioxidants on IAUC of Glucose}

All ten participants completed the glucose control and antioxidant/glucose tests (see Figure 1). The mean IAUC of the glucose control was $258.2 \pm 31.8 \mathrm{mmol} / \mathrm{min} / \mathrm{L}$ (Table 2). The antioxidant-rich food extracts significantly reduced the IAUC compared to the glucose-only 
control (Table 2) with green-tea, alma berry, grape seed and rooibos tea-extracts showing a greater than $30 \%$ reduction in the postprandial glucose response (all $p<0.005$ ). There were no significant differences observed between the food extract groups.

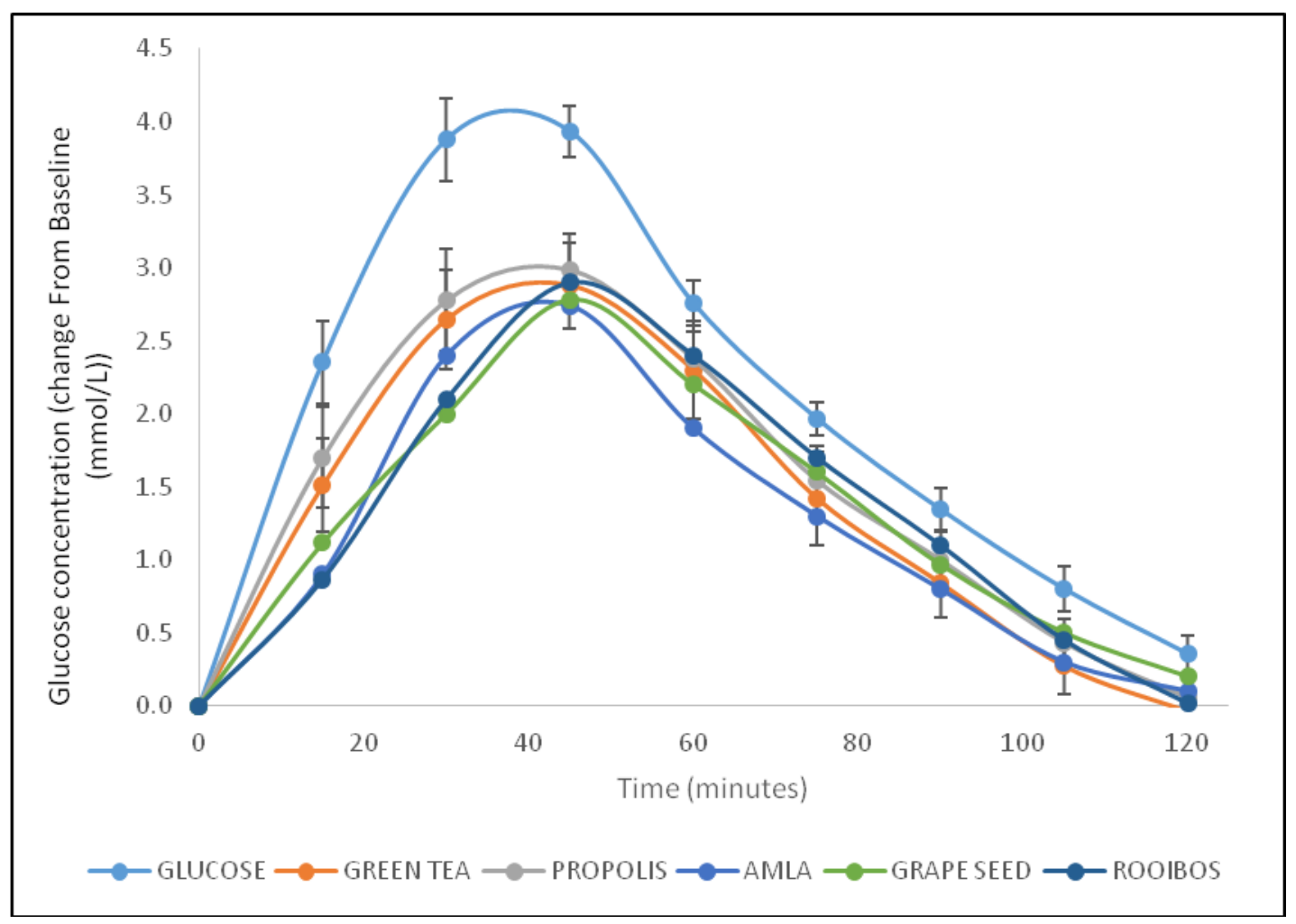

Figure 1: Mean glucose response curve (IAUC; \pm SEM; $n=10$ ) of 50 grams of available carbohydrate from glucose without (control) or with various high-antioxidant extracts taken 10 mins prior to the glucose load. All values are reported as the change from baseline.

Table 2: Mean incremental area under the curve (IAUC) of control samples (50g of available carbohydrate from glucose and/or $50 \mathrm{~g}$ of actual carbohydrate from white bread (103g product) and ham (25g).

\begin{tabular}{|l|c|c|c|c|}
\hline & \multicolumn{2}{|c|}{ Glucose Test } & \multicolumn{2}{c|}{ Bread and Ham Test } \\
\hline & $\begin{array}{c}\text { Mean IAUC } \\
( \pm \text { SD })\end{array}$ & $\begin{array}{c}\text { Reduction } \\
\text { from Control }\end{array}$ & $\begin{array}{c}\text { Mean IAUC } \\
( \pm \text { SD })\end{array}$ & $\begin{array}{c}\text { Reduction } \\
\text { from Control }\end{array}$ \\
\hline Control & $258.2 \pm 31.8$ & - & $192.6 \pm 47.9$ & - \\
\hline + Green Tea & $177.9 \pm 47.4$ & $31.1 \% * *$ & $137.4 \pm 55.0$ & $28.6 \% * *$ \\
\hline + Propolis & $192.8 \pm 46.7$ & $25.3 \% *$ & $143.4 \pm 53.7$ & $25.5 \% *$ \\
\hline + Amla Berry & $156.3 \pm 50.2$ & $39.5 \% * *$ & $146.3 \pm 31.2$ & $24.1 \% * *$ \\
\hline + Grape Seed & $169.6 \pm 38.2$ & $34.3 \% * *$ & $126.2 \pm 60.4$ & $34.4 \% * *$ \\
\hline +Rooibos Tea & $166.6 \pm 20.7$ & $35.5 \% * *$ & $129.2 \pm 33.6$ & $32.9 \% * *$ \\
\hline
\end{tabular}

$* \mathrm{p}<0.05$ vs control, $* * \mathrm{p}<0.005$ vs control 


\section{Study 2: Effects of antioxidants on IAUC of Bread / Ham}

All ten participants completed all bread/ham challenge tests (see Figure 2). The mean IAUC of the $\mathrm{bread} / \mathrm{ham}$ control was $192.6 \pm 47.9 \mathrm{mmol} / \mathrm{min} / \mathrm{L}$ (Table 2). All antioxidant-rich food extracts significantly reduced the IAUC compared to the bread/ham control (Table 2) with grape seed and rooibos tea-extracts showing a greater than $30 \%$ reduction in glucose $(p<0.005)$. There were no significant differences noted between the different antioxidant extracts.

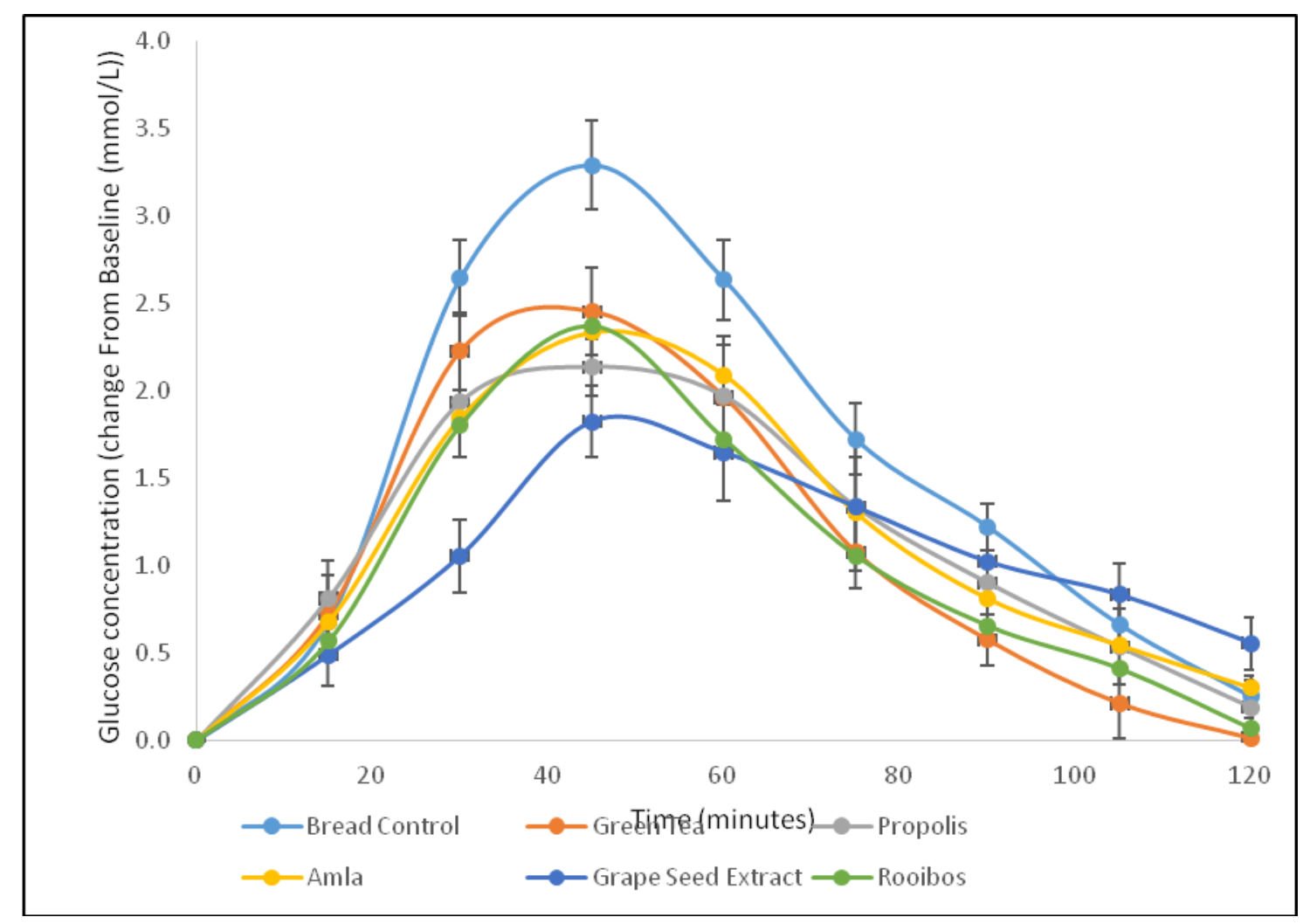

Figure 2: Mean glucose response curve (IAUC; \pm SEM; $n=10$ ) of 50 grams of available carbohydrate from a simple meal without (control) or with various high-antioxidant extracts taken 10 mins prior to the carbohydrate load. All values are reported as the change from baseline.

\section{DISCUSSION}

Diabetes affects more than 380 million people worldwide [2]; current studies and statistics suggest that the prevalence of prediabetes (including both diagnosed and undiagnosed) may be as high as $25-35 \%$ in western populations [33-35], with this disease being correlated to the high rates of obesity seen in these populations [33, 36, 37]. This burden of developing disease is significant, both for the loss in quality of life and the financial costs associated with providing the required healthcare.

The results of this study demonstrate that the five antioxidant-rich extracts tested in this study may act as potential agents to help regulate glycemic control when consuming high-GI foods. This agrees with the results of previous studies that have shown that other food-based 
antioxidants can improve glycemic control in healthy subjects as in those with T2DM [13, 14, 16, 18]. Research suggests that antioxidants may reduce blood glucose levels by affecting carbohydrate digestion in the small intestine due to inhibition of $\alpha$ - glucosidase in gut mucosa $[19,23]$ or inhibition of $\alpha$-amylase, a key enzyme for breaking down starch [23]. Matsui et al. (2004) reported that the bioactive constituents of propolis can inhibit $\alpha$-glucosidase activity [38]. Similarly, epigallocatechin gallate (EGCG), the primary flavonol in green tea, has been shown to inhibit $\alpha$-amylase activity [39] and both grape seed and tea extracts were potent inhibitors of both $\alpha$-amylase and $\alpha$-glucosidase activity in healthy volunteers [40]. In a meta-analysis of 17 randomized controlled trials it has been reported that the beneficial effect of natural antioxidants upon glycemia may be more pronounced in subjects that are at higher risk for metabolic syndrome [41]. This is significant, given that the aim of this study was to assess the effects of these substances in healthy participants as a preparatory step to measure their effects as mediators of glycemic control in prediabetic subjects.

It has been proposed that certain phenolic compounds present in antioxidant-rich extracts may improve the status of at-risk individuals by ameliorating oxidative stress [18, 42], improving insulin sensitivity [22], enhancing the capacity of adipocytes and skeletal muscle for glucose uptake $[43,44]$ and by directly regulating the expression of genes related to the glycemic control $[23,44,45]$. It has been reported that propolis may enhance the activity of key antioxidant enzymes [46] such as superoxide dismutase, catalase and glutathione peroxidase. Increasing the activity of these key antioxidant enzymes can lead to reduction in oxidative damage resulting from hyperglycemia [15]. For this study, the tested food extracts possessed different primary phenolic compounds [30], in combination with other minor antioxidant components. It has been suggested that it is the combination of antioxidants present in the antioxidant-rich food that contributes to its beneficial effects in reducing postprandial glucose levels and improving glycemic control [15]. Significantly, all five of the antioxidant-rich foods demonstrated a strong potential for regulating postprandial glucose levels following carbohydrate consumption which may contribute to lowering the risk of developing diabetes mellitus. However, it is not known whether these extracts exhibited their effects because of inhibition of carbohydrate digestion, amelioration of oxidative stress or other factors. Further research is needed to evaluate the physiological processes through which these extracts are working, particularly if these specific extracts are to be used in further studies involving subjects who have prediabetes or T2DM. It must also be noted that this study was carried out with a small sample size (with capillary blood sampling), and both a larger sample size and/or venous blood sampling could have shown different results. This also needs to be taken into consideration when planning future studies.

Glucose plays an essential role in the maintenance of health, and the ability to tightly regulate glucose levels is essential. However, factors such as poor diet, lack of physical activity and excessive weight all contribute to a prediabetic state where control of glucose and insulin become impaired [3]. Current studies suggest that the prevalence of prediabetes is increasing worldwide, and it is expected that the number of affected individuals will reach $>470$ million in 2030 [3]. The World Health organisation recognises the risk associated with being prediabetic, stating that these individuals are at "high-risk of developing diabetes" [47]. Currently the risk of 
progressing to T2DM is approximately 70\% [1] though research has indicated that both lifestyle and drug interventions in prediabetic subjects can improve glycemic control (thereby reducing the risk of developing T2DM) [6, 48-50] and even cause some to revert back to normoglycemia. However, interventions can only be undertaken when an individual is aware of their condition. It has been suggested that as many as $89 \%$ of prediabetic individuals are unaware of their condition, and even those who are aware are often not well educated on the implications [51]. Furthermore, undiagnosed individuals generally consume higher levels of sugar and carbohydrates than those who are diagnosed, exacerbating the situation further [12]. Simple interventions that can be used by both those with normal glycemic control and those with impaired control are essential if we are to be capable of making any changes in the forecasted prevalence of T2DM.

\section{CONCLUSION:}

Adding antioxidants into the daily diet through consumption of fruit, vegetables and food extracts is a small but effective way to modulate glycemic control, particularly if this is coupled with increased education about the need to consume a healthy diet.

Competing Interests: The authors have no financial interests or conflicts of interest.

\section{Authors' Contributions:}

LC was responsible for study design, analysis and manuscript preparation. RP and HA both contributed to interpretation of results and manuscript preparation.

\section{Acknowledgements and Funding}

Thanks go to Elsie Truter for assistance with blood glucose sampling and to Derek Christie for statistical analysis support. This study was funded in part by Manuka Health NZ Ltd and by the Waiariki Institute of Technology Research Committee.

\section{REFERENCES}

1. American Diabetes Association. Diagnosis and Classification of Diabetes Mellitus. Diabetes Care. 2013;36(1):S67-S74.

2. Beulens J, Grobbee D, Nealb B. The global burden of diabetes and its complications: an emerging pandemic. Eur J Cardiov Prev Res. 2010;17((1 suppl)):s3-s8.

3. Tabák AG, Herder C, Rathmann W, Brunner EJ, Kivimäki M. Prediabetes: a high-risk state for diabetes development. Lancet. 2012;379(9833):2279-90.

4. Boyle JP, Thompson TJ, Gregg EW, Barker LE, Williamson DF. Projection of the year 2050 burden of diabetes in the US adult population: dynamic modeling of incidence, mortality, and prediabetes prevalence. Pop Health Metrics. 2010;8(1):1.

5. Greenwood DC, Threapleton DE, Evans CE, Cleghorn CL, Nykjaer C, Woodhead C, Burley, VJ. Glycemic Index, Glycemic Load, Carbohydrates, and Type 2 Diabetes 
Systematic review and dose-response meta-analysis of prospective studies. Diabetes Care. 2013;36(12):4166-71.

6. Tuomilehto J, Lindström J, Eriksson JG, Valle TT, Hämäläinen H, Ilanne-Parikka P, Keinänen-Kiukaanniemi S, Laakso M, Louheranta A, Rastas M, Salminen V. Prevention of type 2 diabetes mellitus by changes in lifestyle among subjects with impaired glucose tolerance. NE J Med. 2001;344(18):1343-50.

7. Salas-Salvadó J, Bulló M, Babio N, Martínez-González MÁ, Ibarrola-Jurado N, Basora J, Estruch R, Covas MI, Corella D, Arós F, Ruiz-Gutiérrez V. Reduction in the Incidence of Type 2 Diabetes With the Mediterranean Diet Results of the PREDIMED-Reus nutrition intervention randomized trial. Diabetes Care. 2011;34(1):14-9.

8. McLellan KCP, Wyne K, Villagomez ET, Hsueh WA. Therapeutic interventions to reduce the risk of progression from prediabetes to type 2 diabetes mellitus. Ther Clin Risk Manag. 2014;10:173.

9. Bhupathiraju SN, Tobias DK, Malik VS, Pan A, Hruby A, Manson JE, Willett WC, Hu FB. Glycemic index, glycemic load, and risk of type 2 diabetes: results from 3 large US cohorts and an updated meta-analysis. Am J Clin Nutr. 2014:ajcn. 079533.

10. Gakidou E, Mallinger L, Abbott-Klafter J, Guerrero R, Villalpando S, Ridaura RL, Aekplakorn W, Naghavi M, Lim S, Lozano R, Murray CJ. Management of diabetes and associated cardiovascular risk factors in seven countries: a comparison of data from national health examination surveys. Bull World Health Organization. 2011;89(3):17283.

11. Yang Q, Zhang Z, Gregg EW, Flanders WD, Merritt R, Hu FB. Added sugar intake and cardiovascular diseases mortality among US adults. JAMA Int Med. 2014;174(4):51624.

12. Bardenheier BH, Cogswell ME, Gregg EW, Williams DE, Zhang Z, Geiss LS. Does Knowing One's Elevated Glycemic Status Make a Difference in Macronutrient Intake? Diabetes Care. 2014;37(12):3143-9.

13. Deng R. A review of the hypoglycemic effects of five commonly used herbal food supplements. Recent Pat Food Nutr Agric. 2012;4(1):50.

14. Bernardo MA, Silva ML, Santos E, Moncada MM, Brito J, Proença L, Singh J, de Mesquita MF. Effect of Cinnamon Tea on Postprandial Glucose Concentration. J Diabetes Res. 2015;2015.

15. Nasri H, Shirzad H, Baradaran A, Rafieian-kopaei M. Antioxidant plants and diabetes mellitus. J Res Med Sci. 2015;20(5):491.

16. Zheng X-X, Xu Y-L, Li S-H, Hui R, Wu Y-J, Huang X-H. Effects of green tea catechins with or without caffeine on glycemic control in adults: a meta-analysis of randomized controlled trials. Am J Clin Nutr. 2013;97(4):750-62.

17. Li Z, Henning S, Zhang Y, Rahnama N, Zerlin A, Thames G, Tseng CH, Heber D. Decrease of postprandial endothelial dysfunction by spice mix added to high-fat hamburger meat in men with Type 2 diabetes mellitus. Diabetic Medicine. 2013;30(5):590-5. 
18. Annuzzi G, Bozzetto L, Costabile G, Giacco R, Mangione A, Anniballi G, Vitale M, Vetrani C, Cipriano P, Della Corte G, Pasanisi F. Diets naturally rich in polyphenols improve fasting and postprandial dyslipidemia and reduce oxidative stress: a randomized controlled trial. Am J Clin Nutr. 2014;99(3):463-71.

19. Williamson G. Possible effects of dietary polyphenols on sugar absorption and digestion. Mol Nutr Food Res. 2013;57(1):48-57.

20. Murase T, Yokoi Y, Misawa K, Ominami H, Suzuki Y, Shibuya Y, Hase, T. Coffee polyphenols modulate whole-body substrate oxidation and suppress postprandial hyperglycaemia, hyperinsulinaemia and hyperlipidaemia. Br J Nutr. 2012;107(12):175765.

21. Bogani P, Galli C, Villa M, Visioli F. Postprandial anti-inflammatory and antioxidant effects of extra virgin olive oil. Atherosclerosis. 2007;190(1):181-6.

22. Natella F, Belelli F, Gentili V, Ursini F, Scaccini C. Grape seed proanthocyanidins prevent plasma postprandial oxidative stress in humans. J Agric Food Chem. 2002;50(26):7720-5.

23. Pandey KB, Rizvi SI. Plant polyphenols as dietary antioxidants in human health and disease. Oxid Med Cell Longev. 2009;2(5):270-8.

24. Williams JR. The Declaration of Helsinki and public health. BullWorld Health Organization. 2008;86(8):650-2.

25. Josic J, Olsson AT, Wickeberg J, Lindstedt S, Hlebowicz J. Does green tea affect postprandial glucose, insulin and satiety in healthy subjects: a randomized controlled trial. Nutr J. 2010;9(1):1.

26. Törrönen R, Sarkkinen E, Niskanen T, Tapola N, Kilpi K, Niskanen L. Postprandial glucose, insulin and glucagon-like peptide 1 responses to sucrose ingested with berries in healthy subjects. Br J Nutr. 2012;107(10):1445-51.

27. Authority ANZF. Food Standards Code. Rockford, IL, USA: Pierce Chemical Company; 1992.

28. Tolba MF, Azab SS, Khalifa AE, Abdel-Rahman SZ, Abdel-Naim AB. Caffeic acid phenethyl ester, a promising component of propolis with a plethora of biological activities: A review on its anti-inflammatory, neuroprotective, hepatoprotective, and cardioprotective effects. IUBMB Life. 2013;65(8):699-709.

29. Yang CS, Chen L, Lee M-J, Balentine D, Kuo MC, Schantz SP. Blood and urine levels of tea catechins after ingestion of different amounts of green tea by human volunteers. Cancer Epidemiology Biomarkers Prevent. 1998;7(4):351-4.

30. Manach C, Williamson G, Morand C, Scalbert A, Rémésy C. Bioavailability and bioefficacy of polyphenols in humans. I. Review of 97 bioavailability studies. Am J Clin Nutr. 2005;81(1):230S-42S.

31. Liang X-L, Wang X-L, Li Z, Hao Q-H, Wang S-Y. Improved in vitro assays of superoxide anion and 1, 1-diphenyl-2-picrylhydrazyl (DPPH) radical-scavenging activity of isoflavones and isoflavone metabolites. $J$ Agric Food Chem. 2010;58(22):11548-52. 
32. Wolever T, Jenkins D. The use of the glycemic index in predicting the blood glucose response to mixed meals. Am J Clin Nutr.1986;43(1):167-72.

33. Coppell KJ, Mann JI, Williams SM, Jo E, Drury PL, Miller JC, Parnell WR. Prevalence of diagnosed and undiagnosed diabetes and prediabetes in New Zealand: findings from the 2008/09 Adult Nutrition Survey. NZ Med J (Online). 2013;126(1370).

34. Mainous AG, Tanner RJ, Baker R, Zayas CE, Harle CA. Prevalence of prediabetes in England from 2003 to 2011: population-based, cross-sectional study. BMJ open. 2014;4(6):e005002.

35. Bullard KM, Saydah SH, Imperatore G, Cowie CC, Gregg EW, Geiss LS, Cheng YJ, Rolka DB, Williams DE, Caspersen CJ. Secular Changes in US Prediabetes Prevalence Defined by Hemoglobin A1c and Fasting Plasma Glucose National Health and Nutrition Examination Surveys, 1999-2010. Diabetes Care. 2013;36(8):2286-93.

36. Guerrero-Romero F, Rodríguez-Morán M, Pérez-Fuentes R, Sánchez-Guillén MC, González-Ortiz M, Martínez-Abundis E, Brito-Zurita O, Madero A, Figueroa B, RevillaMonsalve C, Flores-Martínez SE. Prediabetes and its relationship with obesity in Mexican adults: the Mexican Diabetes Prevention (MexDiab) Study. Metab Syndr Relat Disord. 2008;6(1):15-23.

37. Neeland IJ, Turer AT, Ayers CR, Powell-Wiley TM, Vega GL, Farzaneh-Far R, Grundy SM, Khera A, McGuire DK, de Lemos JA. Dysfunctional adiposity and the risk of prediabetes and type 2 diabetes in obese adults. Jama. 2012;308(11):1150-9.

38. Matsui T, Ebuchi S, Fujise T, Abesundara KJ, Doi S, Yamada H, Matsumoto K. Strong antihyperglycemic effects of water-soluble fraction of Brazilian propolis and its bioactive constituent, 3, 4, 5-tri-O-caffeoylquinic acid. Biol Pharm Bull. 2004;27(11):1797-803.

39. Forester SC, Gu Y, Lambert JD. Inhibition of starch digestion by the green tea polyphenol,(-)-epigallocatechin-3-gallate. Mol Nutr Food Res. 2012;56(11):1647-54.

40. Yilmazer-Musa M, Griffith AM, Michels AJ, Schneider E, Frei B. Grape seed and tea extracts and catechin 3 -gallates are potent inhibitors of $\alpha$-amylase and $\alpha$-glucosidase activity. J Agric Food Chem. 2012;60(36):8924-9.

41. Liu K, Zhou R, Wang B, Chen K, Shi L-Y, Zhu J-D, Mi MT. Effect of green tea on glucose control and insulin sensitivity: a meta-analysis of 17 randomized controlled trials. Am J Clin Nutr. 2013;98(2):340-8.

42. Rochette L, Zeller M, Cottin Y, Vergely C. Diabetes, oxidative stress and therapeutic strategies. Biochim Biophys Acta (BBA)-General Subjects. 2014;1840(9):2709-29.

43. Yan J, Zhao Y, Suo S, Liu Y, Zhao B. Green tea catechins ameliorate adipose insulin resistance by improving oxidative stress. Free Rad Biol Med. 2012;52(9):1648-57.

44. Ashida H, Furuyashiki T, Nagayasu H, Bessho H, Sakakibara H, Hashimoto T. Antiobesity actions of green tea: possible involvements in modulation of the glucose uptake system and suppression of the adipogenesis-related transcription factors. Biofactors. 2004;22(1-4):135-40. 
45. Cardozo LF, Pedruzzi LM, Stenvinkel P, Stockler-Pinto MB, Daleprane JB, Leite M, Mafra D. Nutritional strategies to modulate inflammation and oxidative stress pathways via activation of the master antioxidant switch Nrf2. Biochimie. 2013;95(8):1525-33.

46. Abo-Salem OM, El-Edel RH, Harisa G, El-Halawany N, Ghonaim MM. Experimental diabetic nephropathy can be prevented by propolis: effect on metabolic disturbances and renal oxidative parameters. Pak J Pharm Sci. 2009;22(2):205-10.

47. Organization WH. Definition and diagnosis of diabetes mellitus and intermediate hyperglycemia: report of a WHO/IDF consultation. Geneva: World Health Organization. 2006.

48. Li G, Zhang P, Wang J, An Y, Gong Q, Gregg EW, Yang W, Zhang B, Shuai Y, Hong J, Engelgau MM.. Cardiovascular mortality, all-cause mortality, and diabetes incidence after lifestyle intervention for people with impaired glucose tolerance in the Da Qing Diabetes Prevention Study: a 23-year follow-up study. Lancet Diabetes Endocrinol. 2014;2(6):474-80.

49. Perreault L, Pan Q, Mather KJ, Watson KE, Hamman RF, Kahn SE, Diabetes Prevention Program Research Group. Effect of regression from prediabetes to normal glucose regulation on long-term reduction in diabetes risk: results from the Diabetes Prevention Program Outcomes Study. Lancet. 2012;379(9833):2243-51.

50. Lindström J, Peltonen M, Eriksson J, Ilanne-Parikka P, Aunola S, KeinänenKiukaanniemi S, Uusitupa M, Tuomilehto J, Finnish Diabetes Prevention Study. Improved lifestyle and decreased diabetes risk over 13 years: long-term follow-up of the randomised Finnish Diabetes Prevention Study (DPS). Diabetologia. 2013;56(2):284-93.

51. Centre for Disease Control and Prevention. Awareness of prediabetes-United States, 2005-2010. MMWR Morbidity and mortality weekly report. 2013;62(11):209. 